\title{
A FILOSOFIA DA DOR NAS CONSOLAÇÕES DE SÊNECA
}

\author{
CLEONICE FURTADO DE MENDONÇA VAN RAIJ* \\ Pontifícia Universidade Católica de Campinas
}

\begin{abstract}
RESUMO: Ao se preocupar com o homem, Sêneca se propôs a encontrar argumentos capazes de ajudá-lo a superar suas paixões, angústias e desordem de alma. Vale ressaltar que, na arte de consolar, o filósofo procura não só expor sua filosofia, mas também entender a dor que abala a pessoa a ser consolada e, ainda, captar a visão de mundo desta, para assim melhor chegar ao seu espirito. Em Sêneca, a dor, embora seja apresentada como um mal universal, como presença certa na vida do homem, não foi trabalhada de modo estritamente convencionado pela tradição consolatória grecoromana, mas, sim, conforme os impulsos de cada situação. Assim, as consolações senequianas - Ad Marciam, Ad Helviam e Ad Polybium - retratam a valorização do homem, cuja grandeza está em entender todas as coisas, em ser superior à dor. O filósofo não concebe um homem submisso, nem a elevação deste pela inserção no todo natural, ao contrário, o vê como um ser superior, que se impõe ao meio, não se deixando vencer pela dor e pelas desgraças humanas.
\end{abstract}

PALAVRAS-CHAVE: Sêneca; consolação; filosofia; dor.

Antes de começarmos a abordar alguns aspectos da filosofia da dor nas Consolações de Sêneca, julgamos interessante ver como a arte de consolar foi trabalhada nos seus primeiros momentos, dando, então, origem ao gênero Consolação.

A história revela-nos que os antigos gregos procuraram aplicar sobre as dores morais remédios puramento físicos. Na Odisséia, Homero tece elogios ao nepenthés, bebida que acreditava ter a propriedade de aliviar e desfazer todas as paixões, ressentimentos e tristezas. Relata ele que Helena acrescentara uma droga maravilhosa ao vinho, o que fizera os parentes dos heróis da guerra, que choravam a lembrança dos familiares e amigos, recuperarem a alegria e o ânimo. A natureza de tal substân- 
cia foi tema de discussão freqüente entre os sábios. Acreditavam alguns tratar-se de ópio, enquanto outros, de chá, vindo do extremo oriente pelo Egito. A crença na eficácia de um remédio físico contra as dores morais não foi de todo abandonada. $\mathrm{O}$ café teve seus partidários, sendo, no século XVII, atribuídas a ele virtudes moralmente calmantes.

$\mathrm{Na}$ Antigüidade, acreditava-se também na virtude de certas palavras mágicas, que combatiam tanto as doenças da alma quanto as do corpo. Segundo Constant Martha (Martha, 1896, p. 138), Catão recuperou uma perna dada por perdida e se fez forte através do emprego de "palavras mágicas".

Era tão difundida a crença nessas palavras que, na Antigüidade, grandes homens e, mesmo com o advento do Cristianismo, alguns cristãos se deixaram enlevar por falsas etimologias. Por exemplo, com base na semelhança da palavra grega balaneîon (banho) com a palavra bállo (expulsar), chegou-se à concepção de que o banho era capaz de expulsar as dores da alma. É assim que um dos mais ilustres padres da Igreja, diante da morte da própria mãe, não sabendo como mitigar a amargura de sua insuportável tristeza, concebeu banhar-se. Em suas Confissões, IX, 30-32, Santo Agostinho, num desabafo de alma diante de tão grande tristeza, fala a Deus que, "não se alimentando mais de palavras vazias, pareceu-lhe bem tomar um banho, por ter ouvido dizer que a palavra latina balneum (banho) provinha da grega balaneîon (expulsar), pois os gregos acreditavam que o banho expulsava da alma a tristeza".

Existiam, como se pode notar, fórmulas especiais para todas as dores.

Provavelmente, já descrentes desses remédios que não mais lhes traziam alívios, os gregos se dirigiram aos homens, num esforço de encontrar em suas palavras um alento. Em Ésquilo, encontramos alusão "às palavras que curam” (Favez, 1937, p. 9), e, nas peças de Eurípedes, as personagens repetem freqüentemente, em meio às queixas, que: "nos sofrimentos, doces são as palavras de um amigo, como é doce um rosto benevolente, e que é necessário ao aflito um amigo, como ao doente, um médico" (id., ib.).

O desejo de consolar nasceu, pois, de uma manifestação espontânea e nobre do coração humano, que visava a atenuar, por meio da palavra, os sofrimentos que angustiavam o homem. Dessa forma, a Consolação é tão antiga quanto o mundo e, a partir do momento em que os homens colocaram seus sentimentos a serviço da dor alheia, a arte de consolar desenvolveu-se até ocupar espaço como "gênero literário”. A primeira manifestação formal dessa arte deu-se através da poesia. Os poetas foram, assim, os primeiros consoladores da humanidade. 
Em Homero (Iliada, VI, 440-493), vemos Heitor que procura consolar Andrômaca, valendo-se do argumento da triste fatalidade das coisas, contra a qual é inútil lutar; ainda na Ilíada, XXIV, 518-551, Aquiles que fez o possível para amenizar a dor do infeliz Príamo; na Odisséia, VI, 187-197, temos Nausícaa que conforta Ulisses, dizendo-lhe distribuir Zeus, por vontade própria, os bens e os males, e que é necessário, então, sofrer e calar. Segundo Innocenzo Negro (Negro, 1925, p. X), Antímaco era conhecido entre os elegíacos por uma elegia que compôs para si mesmo, por ocasião da morte de sua amada. Pertencem também ao gênero consolatório a elegia de Ovídio sobre a morte de Tibulo, bem como os epicédios e algumas lamentações de Píndaro, Simônides e Baquílides, que continham não só louvores aos mortos, mas também razões consolatórias para os sobreviventes.

Foi, entretanto, na Filosofia que a Consolação encontrou campo mais propício ao seu desenvolvimento, dada a influência que ela exercia sobre a vida dos antigos, a ponto de as famílias mais cultas e abastadas cultivarem a presença de um "diretor de Consciência" que, em ocasiões oportunas, se tornava também consolador. Merece citação o exemplo de Areu, filósofo de Augusto, a quem Lívia, segundo Sêneca (Ad Marciam, IV,2), recorreu quando da morte de seu filho Druso, a fim de obter alívio para sua dor.

Segundo Cícero, em uma das passagens das Tusculanas (III, 16, 33), os gregos encontraram, selecionaram e classificaram todas as razões possíveis que pudessem ser oferecidas a qualquer espécie de sofrimento. Serviram-se daquilo que se poderia chamar "escala graduada de Consolações", elaborada por eles próprios, que poderia ser aplicada conforme a ocasião e o mal a ser combatido.

Ao longo do tempo, os consoladores se multiplicaram e, assim, a Consolação foi assumindo aspectos diferentes. Enquanto uns trataram do assunto sob ângulo bastante teórico, fazendo obras de caráter geral - por exemplo, Demócrito: Sobre a tranqüilidade da alma; Sobre o bem estar; Crisipo: Sobre as paixões; Sobre o exílio; Sobre a felicidade; Panécio: Sobre o luto; Sobre as paixões, etc. - outros se interessaram por casos particulares, compondo pequenos tratados, muitas vezes sob a forma de carta, onde se desenvolvia um tema de caráter ético, objetivando convencer o leitor - por exemplo, Plutarco de Queronéia: Sobre o desterro, endereçada a um amigo, exilado numa ilha do mar Egeu; Para Apolônio, dirigida a um amigo que perdera o filho; Cícero: A Torquato, a fim de aliviar-lhe o peso das frustrações políticas; A Bruto, para consolá-lo da morte da mulher Pórcia, etc. --

Médicos da alma, os consoladores se julgavam indispensáveis, mostrando-se sempre prontos a socorrer os desfavorecidos da sorte, mesmo sem serem solicitados, com argumentos prévia e cuidadosamente preparados para combater os males que 
mais afligiam o homem, como a doença, a velhice, a pobreza, o exílio e, o maior deles, a morte. Para cada um desses males, os consoladores já tinham argumentos prontos, prévia e cuidadosamente preparados, razão por que Martha (Favez, 1937, p. 11) dizia "ser a ciência da Consolação uma ciência já completa. Uma espécie de farmácia moral disposta na perfeição. Bastava tão somente que se abrisse a gaveta correspondente ao mal dado, para que se encontrasse imediatamente os remédios mais apropriados à cura do mesmo".

O gênero literário Consolação foi cultivado por todas as grandes escolas filosóficas, às quais encontramos filiados ilustres nomes, insistindo os diferentes filósofos em permanecer fiéis aos princípios de sua escola. Ao se preocuparem com o homem, não negligenciaram suas paixões, angústias e desordens da alma, propondo-se encontrar argumentos capazes de atenuá-las.

Em linhas gerais, todas as Consolações se parecem. Todas deram prioridade a um exagerado intelectualismo, em prejuízo do sentimento. Estavam submetidas quase que a um mesmo plano: introdução, na qual o autor anunciava o mal que tencionava tratar e os remédios que desejava aplicar; a Consolação propriamente dita, dividida em duas partes: a primeira tratava da pessoa aflita; a segunda voltavase para as causas da aflição; seguia, enfim, a conclusão.

Embora existissem divergências, aos poucos foi surgindo entre os autores de Consolações uma espécie de convenção que estipulava algumas medidas a serem seguidas. Uma questão preliminar, a que os consoladores antigos atribuíram uma certa importância, era aquela de saberem qual o momento mais oportuno para se dirigirem ao aflito. Entendiam alguns ser preciso aguardar uma ocasião favorável. Era costume deixar passar a primeira tempestade da dor. Assim, Sêneca esperou três anos sem nada fazer sobre a obstinada dor de Márcia (Ad Marciam, I, 7).

Dentre os filósofos gregos, aquele que mais contribuiu para fazer da Consolação um gênero de relevo foi o acadêmico Crantor (330-270 a. C.). Em livro intitulado Sobre o luto, e dirigido a Ipoclo que perdera o filho, ofereceu à dor paternal tudo o que a Filosofia, depois de séculos, acumulara a respeito da vida e da morte. O referido tratado mereceu na Antigüidade extraordinária reputação, mantida até quase o fim do Império.

No desenvolvimento desse gênero literário, aos filósofos sucederam os retores e sofistas que emprestaram um ritmo bem diferente à arte consolatória, graças aos seus ornamentos, às suas abstrações vazias e à sutileza de argumentações. Deixando de lado o calor e a força da argumentação filosófica, a Consolação adquire nova roupagem. Entre aqueles podem ser mencionados o sofista Górgias de Leontinos, Dion Crisóstomo, autor de três cartas consolatórias, e 
Hélio Aristides, que deixou uma carta aos rodienses, consolando-os pelo incêndio de sua cidade.

Entre os filósofos e retores romanos o primeiro que se ocupou desse gênero foi Cícero, por ocasião da morte de sua filha Túlia, quando escreveu uma Consolação, a fim de abrandar a própria dor. Tal Consolação, infelizmente, não chegou até nós, restando dela apenas alguns fragmentos conservados nas Tusculanas.

Sêneca, sem a menor dúvida, foi o mais fecundo escritor latino de Consolações, se considerarmos não só os textos conhecidos sob esse nome, mas também os vários tratados de alto teor consolatório, como De breuitate uitae (Sobre a brevidade da vida), De tranquillitate animi (Sobre a tranqüilidade do espírito), De remediis fortuitorum (Sobre os remédios dos acontecimentos fortuitos) e as cartas que, em grande parte, pertencem a esse gênero, como as LXIII, LXXXI, XCIII e CVII, dirigidas a Lucílio. No entanto, as genuínas Consolações, ou seja, aquelas que mais respondem às exigências da tradição consolatória, são três: Ad Marciam (A Márcia), Ad Helviam (A Hélvia) e Ad Polybium (A Polibio).

Vale ressaltar que Sêneca escreve as três Consolações dentro de uma perspectiva bastante peculiar: procura não só expor sua filosofia, mas também entender a dor que abala a pessoa a ser consolada e, ainda, captar a visão de mundo desta, para assim melhor chegar ao seu espírito. Em Sêneca, a dor, embora seja apresentada como um mal universal, presença certa na vida do homem, não foi trabalhada do modo estritamente convencionado pela Escola, mas, sim, conforme os impulsos de cada situação. Quando no exílio, por exemplo, o filósofo trabalhou com a dor de Hélvia e a de Políbio, sem ignorar a sua própria dor de exilado, apresentando-a multifacetada, fazendo com que cada um dos seus intercolocutores (Hélvia e Políbio) experimentasse um certo aspecto da dor, individualizando-a, haja vista suas reflexões, seus sentimentos não serem os mesmos em ambas as Cartas.

Pode-se, então, inferir que as Consolações Ad Marciam, Ad Helviam e Ad Polybium, mesmo fazendo uso de preceitos sugeridos pela tradição consolatória grecoromana, apresentam-se como uma ruptura, dando surgimento à criação original e única, já que as condições históricas de produção de tais textos estão, por vezes, vinculadas a situações bastante especiais e, em certos aspectos, muito têm a ver com a vida social e política de Sêneca.

\section{Consolatio ad Marciam}

Esta Consolação é dirigida a uma dama da aristocracia romana, Márcia (filha do historiador Aulo Cremúcio Cordo, valente defensor da liberdade e ho- 
mem de profundas convicções republicanas), a quem, duramente atingida por desventuras como a morte do pai e do filho mais velho, vem faltar o outro, Mitílio, jovem de grandes virtudes e a caminho da consagração (Ad Marciam, XII, 3). Tamanho foi seu desespero pela nova perda que, refugiando-se em si mesmo, esquivavase de qualquer tentativa de consolação. Passados três anos da tragédia, o sofrimento da mesma mantinha-se cada vez mais vivo e presente: parecia renovar-se e intensificar-se (ib., I, 7).

Sêneca escreve, então, uma carta consolatória, esperando que seus argumentos servissem de alívio e conforto para a dor que Márcia enfrentava.

A carta é rica de nobres pensamentos sobre os valores da vida, a instabilidade das coisas humanas, sobre o dever de se considerar com serenidade a idéia da morte, presença inevitável em nossa vida e uma libertação de todas as dores; rica em exemplos de homens e mulheres que, em situações semelhantes, deram mostras de extrema fortaleza de espírito. Como centro desses exemplos, Sêneca coloca duas outras mulheres que enfrentaram dores cruéis: Otávia (irmã de Augusto), que jamais se consolou pela perda do filho Marcelo e se entregou a uma dor sem medida, não abandonando o luto das vestes, e Lívia (esposa de Augusto), que também perdeu seu filho Druso, mas que não se deixou destruir pelo sofrimento, ao contrário, viveu corajosamente conservando a lembrança da morte sem menosprezar os vivos.

Espelhando-se nessas experiências de vida, Márcia deve posicionar-se diante de sua própria dor e decidir como livrar-se dela. Sêneca mostra ainda:

Não é natural deixar-se abater pela dor; a mesma perda fere mais as mulheres que os homens, mais os bárbaros que os homens de raça mansa e civilizada, mais os ignorantes que as pessoas cultas (Ad Marciam, VII, 3).

O filósofo termina a carta introduzindo no seu discurso o pai de Márcia, que desce do céu, onde vive com Mitílio e outras nobres almas, para confortála. Neste ponto, a morte é tratada por Sêneca com grande liberdade e independência de juízo, o que deixa transparecer, em muitos aspectos, a visão bem peculiar que este tem da morte. Na carta, enaltece as virtudes e a grandeza da obra de Cremúcio, de quem Márcia tanto se orgulhava. A presença de Cremúcio a falar com a filha e os elogios tecidos ao historiador são recursos que, com certeza, servirão de alento à dor de Márcia, tocando-a emocionalmente, a ponto desta não se entregar completamente à dor pela perda do filho. 


\section{Consolatio ad Helviam}

Em 41, sob o Império de Cláudio, Sêneca é exilado na Córsega. Afastado da mãe e preocupado com a cruel dor que a dilacerava pelo afastamento duro e forçado do filho - seu orgulho, sua vida, sua razão de ser -, dirige-lhe uma carta consolatória, com a qual procura não só distraíla com relatos de fatos da vida familiar (Ad Helviam, II, 4), retomando, inclusive, a figura de uma tia querida, irmã de Hélvia (ib., XIX, 4-6), pormenores de sua saúde e carreira (ib., XIX, 2), mas também persuadi-la de que ele não está demasiadamente mal e de que ela não deve afligir-se por ele nem tampouco por si mesma.

Em suas vivências religiosas entre os celtas, Sêneca encontra conforto para sua nova condição de vida e também reflexões filosóficas que devem convencer a mãe de que ele está bem, ainda que numa ilha selvagem e distante de todos. O filósofo declara a Hélvia que a mudança não exerce ação alguma sobre o espírito: o exilado pode levar consigo as virtudes, que são suas eternas companheiras e que arrebatam do exílio toda a amargura. Os inconvenientes que o acompanham, como a pobreza, a desonra e o desprezo que, segundo a opinião popular, são inerentes ao exílio, não tocam o sábio.

Numa atitude altamente estóica, mostra-lhe o lado agradável, gratificante e até feliz de sua vida na Córsega. Esforça-se por provar que o exílio não é um mal, mas, sim, uma mudança de lugar (ib., VI, 1) conforme as necessidades da alma humana: esta é móvel, desejosa de novidades e, como todas as coisas do universo, não pode permanecer sempre fixa no mesmo lugar. Ao pedir-lhe: "Olha os astros que iluminam o mundo, nenhum deles fica parado" (ib., VI, 7), quer fazê-la crer que essa mobilidade dos astros é uma propriedade que se reflete também na história política dos povos, que sofreram sucessivas migrações, citando inúmeros exemplos de indivíduos e povos inteiros que se estabeleceram em regiões distantes de sua pátria (ib., VII, 8-9).

Essa atitude filosófica herdara da mãe, que sempre tivera fascínio pela filosofia. Por isso, nesse momento difícil para ambos, esse era o único argumento capaz de atenuar a dor de Hélvia e fazê-la compreender e aceitar o desterro do filho.

Preocupado com o sofrimento da mãe, Sêneca aconselha-a a dedicar-se aos estudos filosóficos que ela tanto ama e às outras pessoas queridas da família, recursos que poderão ajudá-la a abrandar a dor da saudade que tanto a machuca com a ausência do filho. 


\section{Consolatio ad Polybium}

Em 43, durante o exílio na Córsega, Sêneca escreveu uma carta consolatória a Políbio - liberto de origem grega e bastante influente junto ao Imperador Cláudio -, a qual tinha por função transmitir ao príncipe memoriais, requerimentos e súplicas dos cidadãos de todas as partes do Império.

A intensa amargura experimentada por Políbio com a perda de um irmão muito querido e que tanto orgulho lhe dera graças às suas grandes virtudes deveria ter sido a única razão, por que Sêneca escreveu essa carta. No entanto, as intenções do filósofo ficaram comprometidas, e o leitor se surpreende, quando confronta esta carta com aquela escrita a Hélvia. Percebe-se, sem dúvida, que aqui o exílio já se apresentava duro ao filósofo, que assim se dirige a Políbio: "Escrevi estas coisas como pude, com a alma já gasta e enfraquecida por uma longa ociosidade" (Ad Polybium, XVIII, 9). Sêneca já não via o exílio com os mesmos olhos de quando escreveu a Consolatio ad Helviam. Dirigindo-se à mãe, como visto, o filósofo negava que o exílio fosse um mal, procurando enaltecê-lo com nobres princípios filosóficos. Para Hélvia, havia dito:

É a alma que nos torna ricos. Esta nos segue no exílio e quando encontra o quanto basta para sustentar o corpo, mesmo nas solidões mais agudas, ela goza dos bens de que é rica (Ad Helviam, XI, 5).

Na Consolação a Polibio, a situação é outra: valendo-se da influência exercida pelo destinatário da carta junto ao Imperador, ao mesmo tempo que procura abrandar a dor do amigo, Sêneca, já cansado do exílio, encontra uma maneira de pedir a clemência do Imperador Cláudio (Ad Polybium, XIII, 1-4), enaltecendo seu desempenho junto ao povo romano e mostrando-o um governante benevolente ao contrastálo com Calígula, seu antecessor, cujos atos de loucura e crueldade são longamente recordados na carta (ib., XVII, 3-6).

A crítica é quase que unânime na consideração de que a Consolação a Políbio é como uma adulação para que Políbio interceda junto a Cláudio em favor de Sêneca.

Acresce, ainda, que, na Consolação a Políbio, Sêneca fala de Cláudio com grande respeito, enquanto que anos mais tarde, depois da morte do Imperador, lança uma sátira, Diui Claudii Apocolocyntosis, na qual não só trata o Imperador falecido de tolo e tirano sanguinário, como também critica sua forma de administrar a justiça e, principalmente, sua forma de governo. 
Alguns, como Diderot e Buresch, tentam negar a autenticidade desta Consolação.

Para Innocenzo Negro, as adulações a Cláudio e Polibio podem ser negadas se se considerar que, nos primeiros anos, o governo de Cláudio foi sábio e justo e que alguns dos seus méritos, como seus conhecimentos históricos e sua bondade para com os exilados, se destacam, quando comparados à crueldade de Calígula. Na defesa de Sêneca, Innocenzo Negro aponta, ainda, algumas obrigações de gratidão que o filósofo deveria ter para com Cláudio, que lhe tinha salvado a vida.

Fica claro, então, que o destinatário de sua carta consolatória é Políbio, mas, na verdade, a mensagem é dirigida ao Imperador Cláudio, a quem a sorte tornara todo-poderoso, com intuito de conseguir deste o favor de voltar a Roma. Tanto é que, em dado momento, o próprio Cláudio passa a ser seu interlocutor direto (Ad Polybium, XIII, 4). Assim, fica em segundo plano a dor do amigo que, no momento, parece ser útil aos planos do filósofo.

Tal súplica, incontestavelmente, supõe, pelo menos, um momento de fraqueza, uma vez que Sêneca faz uso da dor alheia para tirar vantagens pessoais.

Observa-se em Sêneca a valorização do homem, cuja grandeza está em entender todas as coisas, em ser superior à dor. $\mathrm{O}$ filósofo não concebe um homem submisso, nem a elevação deste pela inserção no todo natural, ao contrário, o vê como um ser superior, que se impõe ao meio, não se deixando vencer pela dor e pelas desgraças humanas. Há, aqui, grande contradição com a lei fundamental do Estoicismo, que exige incondicional submissão do homem ao Destino, à ordem da Natureza. Na Consolação a Hélvia, XVI, 1, Sêneca assim se expressa:

Abater-se com uma dor infinita [...] é um estúpido gosto, e não abater-se em absoluto é uma dureza desumana: a melhor medida entre o sentimento e a razão é experimentar a dor e dominá-la.

Diante do exposto, é possível afirmar que o homem ocupa lugar especial na filosofia de Sêneca, que o coloca como capaz de lutar contra a dor, dor esta sempre presente na natureza, constante e certa, sendo comum a todos.

\section{NotA}

* Professora Doutora da PUC de Campinas e Professora Convidada do Programa de Pós-Graduação em Letras Clássicas da FFLCH-USP. 


\section{REFERÊNCIAS BibLIOGRÁFICAS}

ALBERTINE, E. La composition dans les ouvrages philosophiques de Sénèque. Paris: E. de Boccard, 1923.

ELORDUY, E. El estoicismo. Madrid: Instituto "Luis Vives de Filosofia", 1972. 2v.

FAVEZ, C. La consolation latine chrétienne. Paris: J. Vrin, 1937.

FRAILE, G. História de la filosofia. Madrid: La Editorial Catolica, 1965. v. I.

MARTHA, C. Études morales sur l'Antiquité. Paris: Hachette, 1896.

NEGRO, I. Introduzione. In: SENECA. Ad Marciam de Consolatione. Con introduzione e commento di Innocenzo Negro. Napoli: Tommaso Pironti Editore, 1925. p.

SENECA. Ad Marciam de Consolatione. Con introduzione e commento di Innocenzo Negro. Napoli: Tommaso Pironti Editore, 1925.

-. Consolazione a Marcia. Introduzione, testo, traduzione e note a cura di Antonio Traglia. Roma: Edizione dell'Ateneo, 1965.

-. Consolazione a mia madre Elvia. Introduzione, traduzione e note a cura de Maria Salanitro. Roma: Edizioni dell'Ateneo, 1971.

-. Consolazione a Polibio. Introduzione, testo, traduzione e note a cura di Marinella Ceccarini. Roma: Edizioni dell'Ateneo, 1973.

-. Moral essays. London: Harvard University Press, 1979. v. II.

RAIJ, Cleonice Furtado de Mendonça Van. The philosophy of pain in the Consolations of Seneca.

ABSTRACT: Worried about men, Seneca proposed to find arguments capable of helping him to overcome his passions, anguish and disorder of the soul. It is worth pointing out that, in the art of consoling, the philosopher seeks not only to expose his philosophy, but also to understand the pain that affects the person to be consoled and, further more, to grasp his world vision and in this manner to reach his spirit. In Seneca, the pain, although presented as a universal evil, with sure presence in the life of man, was not dealt with in a strict conventional manner, by the Greek-Roman consolatory tradition, but rather according to the impulses of each situation. Thus the senequian consolations - Ad Marciam, Ad Helviam and Ad Polybium - portray the valorization of man, whose greatness is in the understanding all things, in being superior to pain. The philosopher does not conceive a 
submissive man, neither his elevation by the insertion in a natural wholeness, on the contrary, he sees him as a superior being that imposes himself or the environment, not allowing defeat by pain and human disgrace.

KEY WORDS: Seneca; consolation; philosophy; pain. 